Case Report

\title{
Adjustment of Eculizumab Dosage Pattern in Patients with Atypical Hemolytic Uremic Syndrome with Suboptimal Response to Standard Treatment Pattern
}

\author{
Camino García Monteavaro, ${ }^{1}$ Carmen Peralta Roselló, ${ }^{2}$ Borja Quiroga, ${ }^{3,4}$ \\ José María Baltar Martín, ${ }^{1}$ Lorena Castillo Eraso, ${ }^{2}$ Fernando de Álvaro Moreno, ${ }^{4}$ \\ Alberto Martínez Vea, ${ }^{2}$ and María Teresa Visus-Fernández de Manzanos ${ }^{1}$ \\ ${ }^{1}$ Nephrology Service, Hospital San Agustín, Camino de Heros 6, 33401 Avilés, Spain \\ ${ }^{2}$ Nephrology Service, Hospital Universitari Joan XXIII, C/Dr. Mallafrè Guasch 4, 43005 Tarragona, Spain \\ ${ }^{3}$ Nephrology Service, Hospital Universitario de Guadalajara, C/Donante de Sangre s/n, 19002 Guadalajara, Spain \\ ${ }^{4}$ Nephrology Service, Hospitales Madrid, Pl. del Conde del Valle de Súchil 16, 28015 Madrid, Spain \\ Correspondence should be addressed to Camino García Monteavaro; camino1978@hotmail.com
}

Received 8 July 2016; Revised 11 October 2016; Accepted 2 November 2016

Academic Editor: Yoshihide Fujigaki

Copyright (c) 2016 Camino García Monteavaro et al. This is an open access article distributed under the Creative Commons Attribution License, which permits unrestricted use, distribution, and reproduction in any medium, provided the original work is properly cited.

\begin{abstract}
In patients with atypical hemolytic uremic syndrome (aHUS), complement blocking by eculizumab rapidly halts the process of thrombotic microangiopathy and it is associated with clear long-term hematologic and renal improvements. Eculizumab treatment consists of a 4-week initial phase with weekly IV administration of $900 \mathrm{mg}$ doses, followed by a maintenance phase with a $1,200 \mathrm{mg}$ dose in the fifth week and every $14 \pm 2$ days thereafter. We present three patients with aHUS and suboptimal response to eculizumab treatment at the usual administration dosage who showed hematologic and renal improvements after an adjustment in the eculizumab treatment protocol.
\end{abstract}

\section{Introduction}

Atypical hemolytic uremic syndrome (aHUS) is a rare chronic disease clinically defined by nonimmune microangiopathic hemolytic anemia, thrombocytopenia, and acute kidney failure [1]. The underlying histological lesion is a systemic thrombotic microangiopathy (TMA) [1] affecting mainly kidney vessels.

aHUS is caused by deregulation of the activation of the alternative pathway of the complement system on cell surfaces. Such deregulation is determined by genetic disorders (mutations and polymorphisms), which decrease the activity of certain complement inhibiting proteins or increase the function of activating proteins [2-7]. Mutations in one or more complement-regulating proteins have been detected in about $60 \%$ of aHUS patients [8]. In addition, $6-10 \%$ of patients show antibodies targeting the complement factor $\mathrm{H}$ (CFH), resulting in decreased CFH activity [7].
For many years intensive treatment with plasmapheresis or plasma infusion was the first-line treatment for aHUS, but still about $33-40 \%$ of patients died or required dialysis during the first episode, and one year later $65 \%$ showed permanent renal damage requiring dialysis or leading to death $[9,10]$.

Eculizumab (Soliris ${ }^{\circledR}$; Alexion Pharmaceuticals, Connecticut, USA) is a humanized monoclonal antibody that binds C5, blocking its split up into C5a and C5b and thus inhibiting the generation of the membrane-damaging C5b9 complement complex or terminal complement complex (TCC) [11]. In prospective studies the use of eculizumab has been associated with quick and sustained interruption of the complement-mediated TMA and with significant longterm improvements in renal function [12-14]. Currently eculizumab is the new standard of care for aHUS $[8,15]$.

Eculizumab treatment in aHUS has an initial and a maintenance phase. In the 4 -week initial phase, eculizumab IV 
TABLE 1: Eculizumab doses administered to patient 1 and analytical data after the corresponding eculizumab administration.

\begin{tabular}{|c|c|c|c|c|c|c|c|c|}
\hline Phase & $\begin{array}{l}\text { Week: dose } \\
\text { number }\end{array}$ & $\begin{array}{c}\text { ECU } \\
\text { IV (mg) }\end{array}$ & $\begin{array}{c}\text { Platelets } \\
\text { (number/ } \mu \mathrm{L} \text { ) }\end{array}$ & $\begin{array}{l}\text { LDH } \\
\text { (IU/L) }\end{array}$ & $\begin{array}{l}\text { Hemoglobin } \\
(\mathrm{mg} / \mathrm{dL})\end{array}$ & $\begin{array}{l}\text { Haptoglobin } \\
\text { (mg/dL) }\end{array}$ & Schistocytes & $\begin{array}{c}\text { Serum } \\
\text { creatinine } \\
(\mathrm{mg} / \mathrm{dL})\end{array}$ \\
\hline \multirow{4}{*}{ Initiation } & 1: 1 & 900 & 68,000 & 1,270 & 7.5 & $<7.6$ & - & 5.3 \\
\hline & $2: 2$ & 900 & 144,000 & 1,119 & 10.5 & - & - & 3.1 \\
\hline & $3: 3$ & 900 & 214,000 & 1,269 & 9.8 & - & - & 5.2 \\
\hline & $4: 4$ & 900 & 141,000 & 1,135 & 9.2 & $<7.4$ & - & 4.0 \\
\hline \multirow{7}{*}{ Maintenance } & $5: 5$ & 1,200 & 104,000 & - & 8.5 & $<7.4$ & - & 2.9 \\
\hline & $7: 6$ & 1,200 & 52,000 & 1,092 & 9.6 & $<7.4$ & 6 in 10 fields & 2.8 \\
\hline & 9: 7 & 1,500 & 62,000 & 1,099 & 8.0 & $<7.4$ & - & 2.1 \\
\hline & 11: 8 & 1,200 & 85,000 & 1,037 & 9.3 & $<7.4$ & - & 2.1 \\
\hline & 13: 9 & 1,200 & 283,000 & 534 & 7.4 & 80 & - & 2.1 \\
\hline & $15: 10$ & 1,200 & 209,000 & 389 & 11.3 & 140 & 0 & 3.5 \\
\hline & 17: 11 & 1,200 & 188,000 & 342 & 11.4 & 91.4 & - & 2.4 \\
\hline
\end{tabular}

The modified eculizumab dosage pattern is highlighted in bold: the 7 th dose of eculizumab was increased from 1,200 mg to 1,500 mg. Also, it was administered 12 days after the 6 th (2 days earlier than scheduled according to the center's protocol).

ECU: eculizumab; LDH: lactate dehydrogenase.

$900 \mathrm{mg}$ is administered weekly while during the maintenance phase $1,200 \mathrm{mg}$ IV is administered in the 5th week and from that point onwards $1,200 \mathrm{mg}$ every $14 \pm 2$ days [16].

We present three clinical cases with suboptimal response to eculizumab treatment, which improved after adjusting the dose amount and/or interval.

\section{Cases Presentation}

2.1. Case 1. 22-year-old female patient was referred to our center due to renal failure, anemia, and thrombocytopenia with the following blood and urine analysis data: blood: creatinine $(\mathrm{Cr}) 15.3 \mathrm{mg} / \mathrm{dL}$, urea $314 \mathrm{mg} / \mathrm{dL}$, hemoglobin $(\mathrm{Hb})$ $7.3 \mathrm{~g} / \mathrm{dL}$, platelets $36,000 / \mu \mathrm{L}$, lactate dehydrogenase $(\mathrm{LDH})$ 2,975 IU/L, C3 $114 \mathrm{mg} / \mathrm{dL}$, and C4 $24.5 \mathrm{mg} / \mathrm{dL}$; urine: protein $600 \mathrm{mg} / \mathrm{dL}$ and sediment with $10-30$ erythrocytes and 2-4 leukocytes/field.

TMA was suspected and aHUS was diagnosed based on the following observations and required tests results: uremia, thrombocytopenia, and hemolytic anemia, Coombs negative with schistocytes; normal immunologic study; negative viral serologies; ADAMTS-13 94\%, and negative PCR for Shigatoxin-producing E. coli in feces. At first, no disorders were observed in the genetic analysis and no anti-CFH antibodies were detected. However, an extended test performed some months later revealed a CFH/CFHR1 hybrid gene (the exon 6 of the CFHR1 gene is substituted by the exon 23 of the $C F H$ gene). Additionally, the patient carries a risk haplotype for aHUS in $C F H(\mathrm{H} 3)$ in heterozygosis and a risk haplotype in MCP (MCPggaac) in homozygosis.

Renal biopsy showed signs of acute TMA. Glomerular capillaries and vessels were enlarged and congestive with thrombotic phenomena and erythrocyte fragmentation in the lumen. No signs of vasculitis or sclerosis were observed. Immunofluorescence showed presence of fibrinogen on the wall of some vessels and glomeruli. Light deposits of C1q, C3, and IgM and light chains of Kappa and lambda were found with the same distribution pattern.

Hemodialysis treatment was initiated (6 weekly sessions during the first three weeks, interdaily sessions in the following three weeks, and on-demand hypervolemia from the 6 th week onwards) along with plasmapheresis ( 9 sessions on consecutive days) until the diagnosis of aHUS, at which point plasmapheresis was suspended to start eculizumab treatment (day 10 of hospital admission) at usual doses (Table 1).

Renal function was progressively improved to the point of being able to suspend hemodialysis at 10 weeks of treatment but the improvement in hematologic parameters was delayed. During the initial weeks of treatment $\mathrm{LDH}$ remained increased and haptoglobin remained undetectable. At treatment initiation the platelet count was $68,000 / \mu \mathrm{L}$. After the second dose of eculizumab, platelets reached $214,000 / \mu \mathrm{L}$ but decreased progressively thereafter, and prior to the 6 th dose of eculizumab (second maintenance dose: 1,200 mg) the platelet count was $52,000 / \mu \mathrm{L}$. Thus, the 7 th dose of eculizumab was increased to $1,500 \mathrm{mg}$ and it was administered two days earlier. From this point on platelets increased progressively and the following doses were administered according to the usual dose and pattern. After the 8th dose platelets reached $283,000 / \mu \mathrm{L}$ and stayed at levels close to $\sim 200,000 / \mu \mathrm{L}$ from there on.

Five days before the change in the 7 th dose of eculizumab, the levels of C3 (103 mg/dL) and C4 (16.5 mg/dL) were within normal ranges $(90-180 \mathrm{mg} / \mathrm{dL}$ and $10-40 \mathrm{mg} / \mathrm{dL}$, respectively) and the result of the $50 \%$ hemolytic complement (CH50) assay was $1.1 \mathrm{mg} / \mathrm{dL}$ (normal range: 41$113 \mathrm{mg} / \mathrm{dL})$. At the first determination after increasing the dose of eculizumab the C3 and C4 levels were $104 \mathrm{mg} / \mathrm{dL}$ and $30.7 \mathrm{mg} / \mathrm{dL}$, respectively, and the $\mathrm{CH} 50$ was $2.2 \mathrm{mg} / \mathrm{dL}$. During the rest of the follow-up, the levels of C3 and C4 remained within normal ranges and $\mathrm{CH} 50$ ranged between 0.5 and $1.4 \mathrm{mg} / \mathrm{dL}$. 
TABLE 2: Eculizumab doses administered to patient 2 and analytical data after the corresponding eculizumab administration.

\begin{tabular}{|c|c|c|c|c|c|c|c|c|}
\hline Phase & $\begin{array}{l}\text { Week: dose } \\
\text { number }\end{array}$ & $\begin{array}{c}\text { ECU } \\
\text { IV (mg) }\end{array}$ & $\begin{array}{c}\text { Platelets } \\
\text { (number/ } \mu \mathrm{L} \text { ) }\end{array}$ & $\begin{array}{l}\mathrm{LDH} \\
(\mathrm{IU} / \mathrm{L})\end{array}$ & $\begin{array}{l}\text { Hemoglobin } \\
(\mathrm{mg} / \mathrm{dL})\end{array}$ & $\begin{array}{l}\text { Haptoglobin } \\
\quad(\mathrm{mg} / \mathrm{dL})\end{array}$ & $\begin{array}{l}\text { Schistocytes } \\
\text { (\% in blood) }\end{array}$ & $\begin{array}{c}\text { Serum } \\
\text { creatinine } \\
(\mathrm{mg} / \mathrm{dL})\end{array}$ \\
\hline \multirow{4}{*}{ Initiation } & $1: 1$ & 900 & 110,000 & 317 & 8 & $<3$ & 3 & 12.1 \\
\hline & $2: 2$ & 900 & 116,000 & 229 & 9.9 & - & $<1$ & 13.3 \\
\hline & $3: 3$ & 900 & 62,000 & 186 & 10.1 & - & - & 11.2 \\
\hline & $4: 4$ & 900 & 68,000 & - & 8.9 & - & - & - \\
\hline \multirow{7}{*}{ Maintenance } & $5: 5$ & 1,200 & 65,000 & 299 & 7.9 & $<3$ & 0 & 8.3 \\
\hline & $7: 6$ & 1,200 & 84,000 & - & 8.3 & - & 0 & 4.7 \\
\hline & $9: 7$ & 1,200 & 131,000 & 150 & 9.7 & $<3$ & 0 & 5.7 \\
\hline & $12: 8^{*}$ & 1,200 & 189,000 & 143 & 10.6 & - & $<0,01$ & 3.7 \\
\hline & 14: 9 & 1,200 & 208,000 & - & 13.5 & 13 & - & 4.4 \\
\hline & $16: 10$ & 1,200 & 113,000 & 91 & 14.6 & - & - & 4.5 \\
\hline & 18: 11 & 1,200 & 142,000 & 117 & 14.4 & 36 & $<0,1$ & 4.1 \\
\hline
\end{tabular}

The modified eculizumab dosage pattern is highlighted in bold: the 6 th dose of eculizumab was administered 12 days after the 5 th ( 3 days earlier than scheduled according to the center's protocol).

${ }^{*}$ The administration of the 8th dose of eculizumab was delayed 6 days due to bacteriemia.

ECU: eculizumab; LDH: lactate dehydrogenase.

Ten months after the diagnosis the patient showed a glomerular filtration rate (GFR) of $57 \mathrm{~mL} / \mathrm{min} / 1.73 \mathrm{~m}^{2}$ and completely normal hematologic parameters.

As a complication, she presented with difficult-tocontrol arterial hypertension with an episode of hypertensive encephalopathy. However, currently she shows acceptable hypertension control on amlodipine, doxazosin, and furosemide treatment.

2.2. Case 2. 29-year-old male visited the emergency room (ER) due to overall discomfort. Analyses showed thrombocytopenia, microangiopathic hemolytic anemia (with negative direct Coombs test), and acute decrease of renal function $(\mathrm{Cr} 31 \mathrm{mg} / \mathrm{dL})$, requiring immediate hemodialysis and a first plasmapheresis session 12 hours after admission. ADAMTS13 activity was $>5 \%$. He was diagnosed with aHUS, showing low levels of C3 $(53 \mathrm{mg} / \mathrm{dL})$ and CFH $(10.8 \mathrm{mg} / \mathrm{dL})$ and grade 3 malignant hypertension.

Anti-CFH antibodies were not detected in the patient's plasma. The genetic analysis showed two complement-related mutations in heterozygosis: one in exon 2 of the $\mathrm{C} 3$ gene (c193A $>$ C; p.Lys65Gln) and another one in exon 18 of the CFH gene (c.2655del; p.Arg885Serfs ${ }^{*} 13$ ).

After two sessions of plasmapheresis, eculizumab treatment was initiated at the third day after admission (Table 2). Response was suboptimal and after 5 weeks of treatment the platelet count had decreased from $110,000 / \mu \mathrm{L}$ to $65,000 / \mu \mathrm{L}$. Additionally, hemolysis data persisted and the patient presented difficult-to-control hypertension. A renal biopsy was performed 6 weeks after diagnosis, showing data compatible with TMA with $25 \%$ chronicity. Immunofluorescence was negative for Clq, C3, IgA, IgG, IgM, Kappa, and lambda deposits.

Given the patient's evolution, the 6th dose of eculizumab was administered 12 days after the 5th dose instead of 15 days afterwards, which is the center's usual protocol according to the Summary of Product Characteristics (SmPC) [16]. After that, analytical data showed improved LDH values, platelet counts, and hemoglobin levels (Table 2). Therefore, usual maintenance dose intervals (15 days) were resumed. Anemia was controlled with iron and erythropoietin, which was suspended once the $\mathrm{Hb}$ value was normalized.

During the following weeks serum $\mathrm{Cr}$ ranged approximately between 6 and $4 \mathrm{mg} / \mathrm{dL}$ but seemed to be in progressive decline. In fact, hemodialysis (which the patient had been given three times a week) could be suspended at the 8th week of treatment with eculizumab (one week after the administration of the 6 th dose).

The patient had two later hospital admissions, one due to Hickman catheter-related $S$. aureus bacteremia and another one due to possible respiratory infection plus hypertensive crisis. No reactivation of the aHUS was observed during these infections, although administration of the 8th dose of eculizumab had to be delayed by 6 days because of the first event (no relevant changes in the aHUS clinical and analytical parameters were observed).

Six months after admission the patient presented the following analytical parameters: platelets $149,000 / \mu \mathrm{L}, \mathrm{LDH}$ $96 \mathrm{IU} / \mathrm{L}, \mathrm{Hb}$ 10,7 g/dL, haptoglobin $56 \mathrm{mg} / \mathrm{dL}$, serum $\mathrm{Cr}$ $2.37 \mathrm{mg} / \mathrm{dL}$, and GFR $22 \mathrm{~mL} / \mathrm{min} / 1.73 \mathrm{~m}^{2}$. Mean blood pressure was $147 / 108 \mathrm{mmHg}$. Currently arterial pressure is better controlled $(\sim 120 / 85 \mathrm{mmHg})$ under treatment with five antihypertensive drugs: amlodipine/olmesartan $20 \mathrm{mg} / 5 \mathrm{mg}$, doxazosin $8 \mathrm{mg}$, atenolol $50 \mathrm{mg}$, and torasemide $5 \mathrm{mg}$.

2.3. Case 3. 66-year-old female patient with TMA clinical signs was admitted into our center's ER, transferred from a hospital in the United States. Five days prior to hospital admission in the US, where she was on vacation, she started with progressive asthenia, oral intolerance, and 
TABLE 3: Eculizumab doses administered to patient 3 and analytical data after the corresponding eculizumab administration.

\begin{tabular}{|c|c|c|c|c|c|c|c|c|}
\hline Phase & $\begin{array}{c}\text { Week: dose } \\
\text { number }\end{array}$ & $\begin{array}{c}\text { ECU } \\
\text { IV (mg) }\end{array}$ & $\begin{array}{c}\text { Platelets } \\
\text { (number/ } \mu \mathrm{L} \text { ) }\end{array}$ & $\begin{array}{l}\mathrm{LDH} \\
(\mathrm{IU} / \mathrm{L})\end{array}$ & $\begin{array}{l}\text { Hemoglobin } \\
\quad(\mathrm{mg} / \mathrm{dL})\end{array}$ & $\begin{array}{l}\text { Haptoglobin } \\
(\mathrm{mg} / \mathrm{dL})\end{array}$ & $\begin{array}{l}\text { Schistocytes } \\
\text { per field }\end{array}$ & $\begin{array}{c}\text { Serum } \\
\text { creatinine } \\
(\mathrm{mg} / \mathrm{dL})\end{array}$ \\
\hline \multirow{4}{*}{ Initiation } & $1: 1$ & 900 & 93,000 & 728 & 8.3 & Below the limit & $5-8$ & 4.3 \\
\hline & $2: 2$ & 900 & 30,000 & 1,170 & 10.5 & Below the limit & 8 & 5.6 \\
\hline & $3: 3$ & 900 & 81,000 & 1,957 & 9 & - & - & $6.5^{* *}$ \\
\hline & 4: 4 & 900 & 71,000 & 1,230 & 7.8 & Below the limit & $7-10$ & 0.9 \\
\hline \multirow{5}{*}{ Maintenance } & $5: 5^{*}$ & 1,500 & 64,000 & 1,675 & 10.5 & Below the limit & - & 2.3 \\
\hline & $7: 6$ & 1,500 & 135,000 & 1,483 & 7.9 & - & 0 & 2.5 \\
\hline & 9: 7 & 1,200 & 297,000 & 794 & 8.2 & 249 & 0 & 4.3 \\
\hline & 11: 8 & 1,200 & 198,000 & 811 & 9 & 99 & 0 & 5.3 \\
\hline & 13: 9 & 1,200 & 269,000 & 560 & 9.2 & - & - & 5.2 \\
\hline
\end{tabular}

The modified eculizumab dosage pattern is highlighted in bold: the 5 th and 6 th doses of eculizumab were increased from $1,200 \mathrm{mg}$ to $1,500 \mathrm{mg}$.

${ }^{*}$ Initiation of rituximab. ${ }^{* *}$ The patient was admitted into the ICU due to acute lung edema at the third week of treatment with eculizumab. There she was intubated and started on continuous venovenous hemofiltration and empiric wide-spectrum antibiotherapy. The patient showed good evolution and was discharged from the ICU one week later.

ECU: Eculizumab; LDH: Lactate dehydrogenase; ICU: Intensive care unit.

minimum effort dyspnea plus severe headache. According to the US clinical history, on admission she presented with hemolytic anemia ( $\mathrm{Hb} 6 \mathrm{~g} / \mathrm{dL}, \mathrm{LDH}>1,200 \mathrm{IU} / \mathrm{L}$, haptoglobin undetectable, and schistocytes positive), thrombocytopenia (91,000 platelets/ $\mu \mathrm{L}$ ), and acute renal failure (serum Cr $7 \mathrm{mg} / \mathrm{dL}$ ). Anti-nuclear antibodies, anti-DNA antibodies, anti-neutrophil cytoplasmic antibodies, antiglomerular basal membrane antibodies, and rheumatoid factor were all negative. The patient was treated with hemodialysis and plasmapheresis. In addition, she received erythrocyte transfusions ( 5 concentrates), IV corticosteroids, and 5 daily plasmapheresis sessions before returning to Spain.

On admission to our center, she presented with oliguria, arterial pressure $150 / 90 \mathrm{mmHg}$, edema in inferior limbs, ascites, and disseminated crepitation at pulmonary auscultation. Chest X-ray showed bilateral pleural effusions. In laboratory data she showed decreased renal function (serum Cr $4.1 \mathrm{mg} / \mathrm{dL}$ ), nonimmune hemolytic anemia $(\mathrm{Hb} 11.0 \mathrm{~g} / \mathrm{dL}$; LDH 1,119 IU/L, 7-8 schistocytes per field and direct Coombs test negative) and thrombocytopenia $(148,000 / \mu \mathrm{L})$. C3 and C4 levels were $60.6 \mathrm{mg} / \mathrm{dL}$ and $6.7 \mathrm{mg} / \mathrm{dL}$, respectively. The patient started hemodialysis and plasmapheresis while waiting for the results of ADAMTS-13 activity and a renal biopsy for diagnosis. ADAMTS-13 activity was 43\%, suggesting the diagnosis of aHUS. The histopathological data from the renal biopsy was consistent with TMA: out of the 20 glomeruli obtained in the biopsy, one was sclerotic and the others showed diffuse lesion with extensive mesangiolysis, sclerosis of capillary loops, and occasional fibrin thrombi; frequent luminal occlusion of helium arterioles with moderate interstitial fibrosis was also observed; and muscular arteries presented with myxoid thickening of the intima with luminal obliteration and presence of fragmented erythrocytes in the parietal zone. Anti-FH antibodies were negative and the genetic complement study showed no disorders.

Eculizumab treatment was initiated according to the SmPC (900 mg/weekly during 4 weeks followed by 1,200 mg every 15 days) along with antimeningococcus prophylaxis (Table 3). Few days after the first eculizumab infusion, the platelet count and the LDH levels worsened and hemodialysis-dependent acute renal failure persisted. Thus, one plasmapheresis session was administered previous to the second infusion of eculizumab. At the third week of treatment, the patient showed dyspnea and X-ray data compatible with acute lung edema with hemodynamic instability to ultrafiltration; as a result she was admitted into the intensive care unit (ICU), where she was intubated and started on continuous venovenous hemofiltration and empiric widespectrum antibiotherapy. The patient showed good evolution and negative cultures, except for CMV PCR which was positive, and was treated with ganciclovir, and she was discharged from the ICU one week later.

At the 4th week of treatment, the patient received the last initiation dose of eculizumab $(900 \mathrm{mg})$. However, the platelet count remained low and the levels of LDH remained elevated. Thus, rituximab was initiated at the fifth week, associated with the corresponding first maintenance eculizumab dose (fifth dose), which was increased from $1,200 \mathrm{mg}$ to $1,500 \mathrm{mg}$. From that point on platelet count improved and LDH decreased (Table 3). Consequently, after the 6th administration of eculizumab the maintenance dosing pattern was back to the usual 1,200 mg every 15 days and the patient was discharged from the hospital 10 weeks after admission. She has remained on hemodialysis up until now, with no new hemolysis data.

\section{Discussion}

Due to genetic and immune reasons, deregulation and overactivation of the alternative complement pathway on cell surfaces underlay the pathogenesis of aHUS. Approximately $60 \%$ of patients with aHUS show isolated or combined mutations in genes encoding complement regulatory factors, and $10 \%$ present acquired antibodies targeting CFH $[1,17-$ 19]. Mutations include loss-of-function mutations of genes 
coding for $\mathrm{CFH}$, membrane cofactor protein (MCP), complement factor I (CFI), and thrombomodulin (THBD) and gain-of-function mutations of genes coding for complement factor B and complement component 3 [1, 3, 17, 19-21]. In addition, mutations and genetic polymorphisms of $\mathrm{CFH}-$ related proteins (CFHR) may also be the underlying cause of aHUS [21-23]. As a consequence of these alterations, when the complement is activated by a variety of triggering factors (such as infections), its activity on own cells cannot be controlled properly and endothelial damage, inflammation, and thrombosis are caused.

Patient 1 showed a CFH/CFHR1 hybrid gene and two risk haplotypes for aHUS and patient 2 showed mutations in $\mathrm{CFH}$ and $C 3$, supporting the idea that multiple hits in complement components are necessary for the development of aHUS in some patients [24]. Genomic rearrangements of the $\mathrm{CFH}$ and the CFHR gene region lead to novel fusion proteins and have been previously observed in patients with aHUS [2528]. The C3 mutation found in patient 2 has been observed to decrease $\mathrm{C} 3 \mathrm{~b}$ binding to $\mathrm{CFH}$, a fact that may lead to impaired C3b inactivation [29]. However, the $\mathrm{CFH}$ mutation carried by this patient is not among those commonly reported [30]. The structural and functional consequences of the amino acid change in the protein sequence originated by this mutation are still to be assessed. In contrast, patient 3 did not show any mutations in the complement fraction or anti-CFH antibodies. In this regard, it has been suggested that in this kind of patients aHUS would probably develop due to the existence of still unrecognized genetic or acquired complement disorders [31]. An in vitro study showed that sera from patients with aHUS without identified mutations or anti-CFH antibodies still induced more intense $\mathrm{C} 3$ and C5b9 deposits on adenosine 5-diphosphate- (ADP-) activated human microvascular endothelial cells than control sera, which supported the existence of other inherited or acquired complement disorders [31].

The efficacy and safety of eculizumab were firstly established in two 26-week prospective, multicenter, controlled, and open studies, with a mean extension period of 62 weeks, in 37 aHUS patients resistant to plasma exchange/infusion or with chronic plasma exchange/infusion treatment [12]. Clinical benefits regarding hematologic values, TMA-eventfree status, and renal parameters were significant at 6 months and were sustained at two and three years of treatment, independently of the mutation status of the patients $[13,14]$. The dosing schedule of eculizumab for patients with aHUS was confirmed in those two original trials and proved to be sufficient to achieve and maintain the minimum serum concentration of eculizumab required to block terminal complement activation [12].

Initially our patients did not respond to eculizumab as expected. Although renal function improved progressively in patient 1 , platelet counts decreased during the maintenance phase; thus, the 7th dose of treatment was increased (from 1,200 to $1,500 \mathrm{mg}$ ) and administered two days earlier in a successful attempt to improve hematologic data. Since the maintenance administration pattern is $14 \pm 2$ days, although the amount of dose was higher than recommended, the period of administration was still within the SmPC indications [16]. Likewise, patient 2 received the 6th dose three days earlier than the usual center protocol, and since that protocol had a 15-day interval between maintenance doses, the administration at 12 days was also within the SmPC indications. In patient 3 , clinical response was poor after the administration of the initiation phase of eculizumab; thus, the first and second maintenance doses were increased from 1,200 to $1,500 \mathrm{mg}$, and concomitant rituximab was started, showing thereafter an improvement in hematologic data.

Before the marketing of eculizumab, the anti-DC20 chimeric monoclonal antibody rituximab was sometimes used as part of the conventional therapy for aHUS, including support treatment with plasmapheresis in patients with aHUS and anti-CFH antibodies, used in general with low success rates [9]. However, rituximab has sometimes been used successfully, helping platelet recovery and clinical improvement in atypical as well as gemcitabine-related HUS cases [32,33]. Thus, a possible effect of the administration of rituximab on the improvement observed in patient 3 , together with the increases in the fifth and sixth doses of eculizumab, cannot be excluded.

Suboptimal response to eculizumab therapy has been reported in few previous cases. In some Asian patients with paroxysmal nocturnal hemoglobinuria $(\mathrm{PNH})$, a missense mutation in the $\mathrm{C} 5$ gene has been associated with poor treatment response $[34,35]$. Recently the case of a patient with aHUS carrying a novel truncating $\mathrm{CFH}$ mutation in combination with other changes known to be associated with aHUS, who presented frequent relapses of the disease despite eculizumab treatment, has been reported [36]. Therefore, as mentioned, there might still be unrecognized genetic or acquired complement disorders leading to aHUS [31], some of which might respond in a lesser degree to eculizumab treatment.

The complement blockade with eculizumab in 22 patients with PNH has been assessed in a recent study, suggesting that there might be an important variability in the response [37]. The residual functional activity of C5 was screened using a $\mathrm{CH} 50$ assay, which is sensitive to changes in the activity of the components of the terminal complement pathway. Lack of detectable CH50 activity ( $\leq 10 \%$ of normal values) was found in $51 \%$ of the samples and was directly related to circulating free eculizumab levels. In this regard, low free eculizumab levels $(<50 \mathrm{mg} / \mathrm{mL})$ correlated with detectable CH50 activity, elevated bilirubin levels, and the need for transfusions. The authors have concluded that concomitant assessment of $\mathrm{CH} 50$ and circulating free eculizumab levels may be useful for monitoring complement blockade in patients treated with eculizumab in order to detect possible underdosing [37]. Similarly, the determination of the functional alternative complement pathway using a APH50 assay has also been used in the assessment of the response to eculizumab in patients with aHUS [38]. However, it must be taken into account that $\mathrm{CH} 50$, which measures the functional activity of the classical complement pathway, is a nonspecific indirect way of measuring the activity of eculizumab and its usefulness in the clinical setting remains controversial [39]. Currently, not all the Spanish centers have included in their aHUS protocols the determination of $\mathrm{CH} 50$ or APH50, and the clinical evolution 
of the patient continues to be a key factor for the assessment of the response to eculizumab and the modification of the treatment pattern.

In this regard, no data is available regarding these parameters for patients 2 and 3 . In patient 1 , lab analyses showed that $\mathrm{CH} 50$ was low after the first six doses of eculizumab $(\sim 1 \mathrm{mg} / \mathrm{dL})$, suggesting an effective inhibition of the terminal complement sequence. However, the platelet count continued to decrease and it was decided to increase the 7th dose of eculizumab (which was also administered earlier). As expected, $\mathrm{CH} 50$ continued to be low after this treatment change, but an improvement in hematologic data was observed. The levels of $\mathrm{C} 3$ and $\mathrm{C} 4$ were within normal ranges all the time.

In conclusion, the reason why the patients with aHUS reported in this paper had a suboptimal response to eculizumab remains unknown. However, at least in these cases adjusting the interval of eculizumab administration or increasing the dose were successful strategies. Thus, such temporary management strategies should be considered in patients with aHUS with persistent suboptimal response to eculizumab.

\section{Competing Interests}

The authors declare that there are no competing interests regarding the publication of this paper.

\section{References}

[1] C. Loirat and V. Frémeaux-Bacchi, "Atypical hemolytic uremic syndrome," Orphanet Journal of Rare Diseases, vol. 6, no. 1, article 60, 2011.

[2] P. Warwicker, T. H. J. Goodship, R. L. Donne et al., "Genetic studies into inherited and sporadic hemolytic uremic syndrome," Kidney International, vol. 53, no. 4, pp. 836-844, 1998.

[3] D. Kavanagh, E. J. Kemp, E. Mayland et al., "Mutations in complement factor I predispose to development of atypical hemolytic uremic syndrome," Journal of the American Society of Nephrology, vol. 16, no. 7, pp. 2150-2155, 2005.

[4] P. F. Zipfel, M. Edey, S. Heinen et al., "Deletion of complement factor H-related genes CFHR1 and CFHR3 is associated with atypical hemolytic uremic syndrome," PLoS Genetics, vol. 3, article e41, 2007.

[5] E. Goicoechea de Jorge, C. L. Harris, J. Esparza-Gordillo et al., "Gain-of-function mutations in complement factor B are associated with atypical hemolytic uremic syndrome," Proceedings of the National Academy of Sciences of the United States of America, vol. 104, no. 1, pp. 240-245, 2007.

[6] V. Frémeaux-Bacchi, E. C. Miller, M. K. Liszewski et al., "Mutations in complement C3 predispose to development of atypical hemolytic uremic syndrome," Blood, vol. 112, no. 13, pp. 4948-4952, 2008.

[7] M.-A. Dragon-Durey, S. K. Sethi, A. Bagga et al., "Clinical features of anti-factor $\mathrm{H}$ autoantibody-associated hemolytic uremic syndrome," Journal of the American Society of Nephrology, vol. 21, no. 12, pp. 2180-2187, 2010.

[8] J. M. Campistol, M. Arias, G. Ariceta et al., "An update for atypical haemolytic uraemic syndrome: diagnosis and treatment. A consensus document," Nefrologia, vol. 35, no. 5, pp. 421-447, 2015.

[9] C. Loirat, J. Saland, and M. Bitzan, "Management of hemolytic uremic syndrome," La Presse Médicale, vol. 41, no. 3, pp. el15e135, 2012.

[10] J. Caprioli, M. Noris, S. Brioschi et al., "Genetics of HUS: the impact of MCP, CFH, and IF mutations on clinical presentation, response to treatment, and outcome," Blood, vol. 108, no. 4, pp. 1267-1279, 2006.

[11] M. Kaplan, "Eculizumab (Alexion)," Current Opinion in Investigational Drugs, vol. 3, pp. 1017-1023, 2002.

[12] C. M. Legendre, C. Licht, P. Muus et al., "Terminal complement inhibitor eculizumab in atypical hemolytic-uremic syndrome," The New England Journal of Medicine, vol. 368, no. 23, pp. 21692181, 2013.

[13] C. Licht, L. A. Greenbaum, P. Muus et al., "Efficacy and safety of eculizumab in atypical hemolytic uremic syndrome from 2-year extensions of phase 2 studies," Kidney International, vol. 87, no. 5, pp. 1061-1073, 2015.

[14] A. O. Gaber, C. Loirat, L. Greenbaum et al., "Eculizumab (ECU) maintains efficacy in atypical hemolytic uremic syndrome (aHUS) patients (Pts) with progressing thrombotic microangiopathy (TMA): 3-year (Yr) update," Journal of the American Society of Nephrology, vol. 24, article 822A, 2013.

[15] J. Zuber, F. Fakhouri, L. T. Roumenina, C. Loirat, and V. Frémeaux-Bacchi, "Use of eculizumab for atypical haemolytic uraemic syndrome and C3 glomerulopathies," Nature Reviews Nephrology, vol. 8, no. 11, pp. 643-657, 2012.

[16] Alexion Pharmaceuticals Inc, "Soliris (eculizumab) summary of product characteristics," http://www.ema.europa.eu/docs/en_ GB/document_library/EPAR_-_Product_Information/human/ 000791/WC500054208.pdf.

[17] M. Noris and G. Remuzzi, "Hemolytic uremic syndrome," Journal of the American Society of Nephrology, vol. 16, no. 4, pp. 1035-1050, 2005.

[18] D. Westra, E. Volokhina, E. Van Der Heijden et al., "Genetic disorders in complement (regulating) genes in patients with atypical haemolytic uraemic syndrome (aHUS)," Nephrology Dialysis Transplantation, vol. 25, no. 7, pp. 2195-2202, 2010.

[19] T. K. Maga, C. J. Nishimura, A. E. Weaver, K. L. Frees, and R. J. H. Smith, "Mutations in alternative pathway complement proteins in American patients with atypical hemolytic uremic syndrome," Human Mutation, vol. 31, no. 6, pp. E1445-E1460, 2010.

[20] D. Kavanagh, A. Richards, M. Noris et al., "Characterization of mutations in complement factor I (CFI) associated with hemolytic uremic syndrome," Molecular Immunology, vol. 45, no. 1, pp. 95-105, 2008.

[21] S. Alasfar and N. Alachkar, "Atypical hemolytic uremic syndrome post-kidney transplantation: two case reports and review of the literature," Frontiers in Medicine, vol. 1, article 52, 2014.

[22] I. Moore, L. Strain, I. Pappworth et al., "Association of factor $\mathrm{H}$ autoantibodies with deletions of CFHR1, CFHR3, CFHR4, and with mutations in $\mathrm{CFH}, \mathrm{CFI}, \mathrm{CD} 46$, and $\mathrm{C} 3$ in patients with atypical hemolytic uremic syndrome," Blood, vol. 115, no. 2, pp. 379-387, 2010.

[23] P. F. Zipfel, C. Mache, D. Müller, C. Licht, M. Wigger, and C. Skerka, "DEAP-HUS: deficiency of CFHR plasma proteins and autoantibody-positive form of hemolytic uremic syndrome," Pediatric Nephrology, vol. 25, no. 10, pp. 2009-2019, 2010.

[24] S. Rodriguez de Córdoba, "aHUS: a disorder with many risk factors," Blood, vol. 115, no. 2, pp. 158-160, 2010. 
[25] J. P. Venables, L. Strain, D. Routledge et al., "Atypical haemolytic uraemic syndrome associated with a hybrid complement gene," PLoS Medicine, vol. 3, article e431, 2006.

[26] C. Nester, Z. Stewart, D. Myers et al., "Pre-emptive eculizumab and plasmapheresis for renal transplant in atypical hemolytic uremic syndrome," Clinical Journal of the American Society of Nephrology, vol. 6, no. 6, pp. 1488-1494, 2011.

[27] S. Krid, L. T. Roumenina, D. Beury et al., "Renal transplantation under prophylactic eculizumab in atypical hemolytic uremic syndrome with CFH/CFHR1 hybrid protein," American Journal of Transplantation, vol. 12, no. 7, pp. 1938-1944, 2012.

[28] E. Román-Ortiz, S. Mendizabal Oteiza, S. Pinto, M. LópezTrascasa, P. Sánchez-Corral, and S. Rodríguez de Cordoba, "Eculizumab long-term therapy for pediatric renal transplant in aHUS with CFH/CFHR1 hybrid gene," Pediatric Nephrology, vol. 29, no. 1, pp. 149-153, 2014.

[29] E. Volokhina, D. Westra, X. Xue, P. Gros, N. Van De Kar, and L. Van Den Heuvel, "Novel C3 mutation p.Lys65Gln in aHUS affects complement factor H binding," Pediatric Nephrology, vol. 27, no. 9, pp. 1519-1524, 2012.

[30] D. Kavanagh, T. H. Goodship, and A. Richards, "Atypical hemolytic uremic syndrome," Seminars in Nephrology, vol. 33, no. 6, pp. 508-530, 2013.

[31] M. Noris, M. Galbusera, S. Gastoldi et al., "Dynamics of complement activation in aHUS and how to monitor eculizumab therapy," Blood, vol. 124, no. 11, pp. 1715-1726, 2014.

[32] A. Bharthuar, L. Egloff, J. Becker et al., "Rituximab-based therapy for gemcitabine-induced hemolytic uremic syndrome in a patient with metastatic pancreatic adenocarcinoma: a case report," Cancer Chemotherapy and Pharmacology, vol. 64, no. 1, pp. 177-181, 2009.

[33] A. Lionet, F. Provôt, F. Glowacki, V. Frémeaux-Bacchi, and M. Hazzan, "A case of adult atypical haemolytic uraemic syndrome related to anti-factor $\mathrm{H}$ autoantibodies successfully treated by plasma exchange, corticosteroids and rituximab," NDT Plus, vol. 2, no. 6, pp. 458-460, 2009.

[34] J. Nishimura, M. Yamamoto, S. Hayashi et al., "Genetic variants in C5 and poor response to eculizumab," The New England Journal of Medicine, vol. 370, no. 7, pp. 632-639, 2014.

[35] J.-I. Nishimura and Y. Kanakura, “The C5 gene polymorphism in patients with PNH," [Rinshō Ketsueki], vol. 56, no. 2, pp. 103110, 2015.

[36] G. Schalk, M. Kirschfink, C. Wehling et al., "A complicated case of atypical hemolytic uremic syndrome with frequent relapses under eculizumab," Pediatric Nephrology, vol. 30, no. 6, pp. 1039-1042, 2015.

[37] R. P. De Latour, V. Fremeaux-Bacchi, R. Porcher et al., "Assessing complement blockade in patients with paroxysmal nocturnal hemoglobinuria receiving eculizumab," Blood, vol. 125, no. 5, pp. 775-783, 2015.

[38] C. J. Mache, B. Acham-Roschitz, V. Frémeaux-Bacchi et al., "Complement inhibitor eculizumab in atypical hemolytic uremic syndrome," Clinical Journal of the American Society of Nephrology, vol. 4, no. 8, pp. 1312-1316, 2009.

[39] E. Contreras, J. de la Rubia, J. Del Río-Garma, M. Díaz-Ricart, J. M. García-Gala, and M. Lozano, "Diagnostic and therapeutic guidelines of thrombotic microangiopathies of the Spanish Apheresis Group," Medicina Clinica, vol. 144, no. 7, pp. 331331.e13, 2015. 


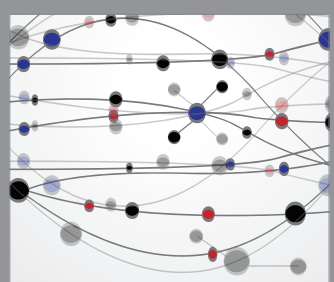

The Scientific World Journal
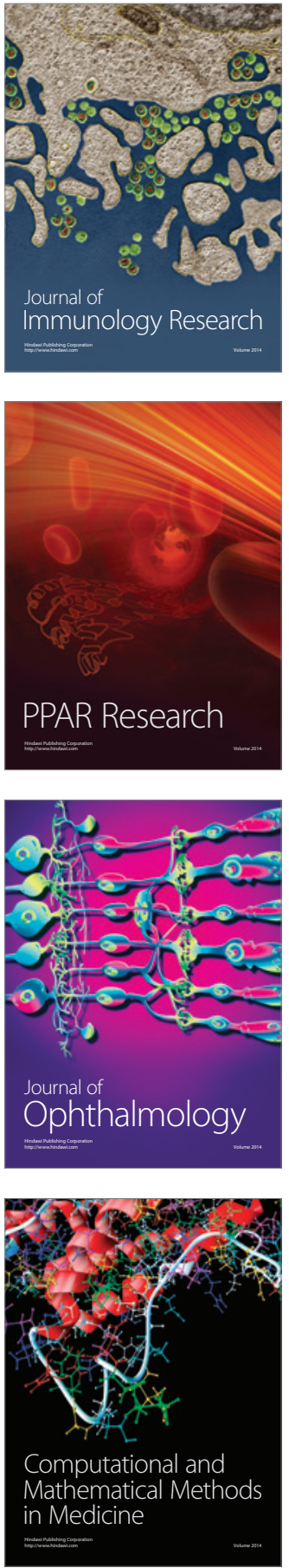

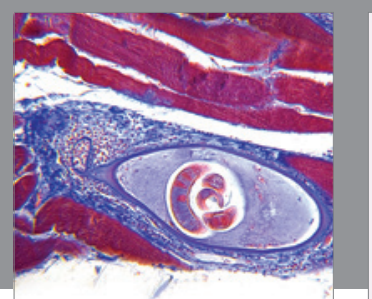

Gastroenterology Research and Practice

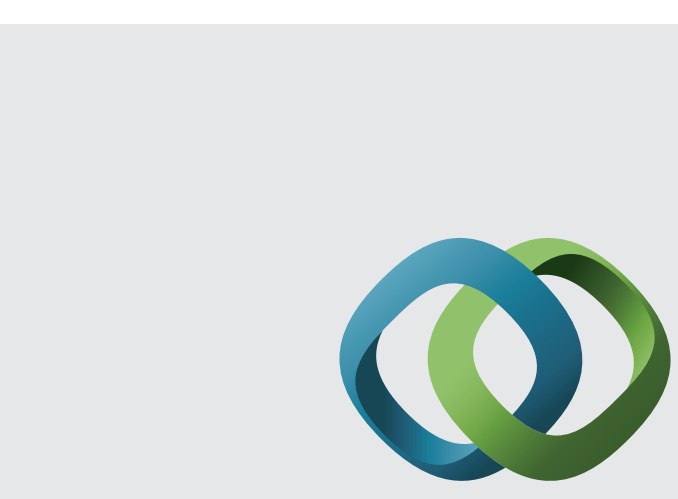

\section{Hindawi}

Submit your manuscripts at

http://www.hindawi.com
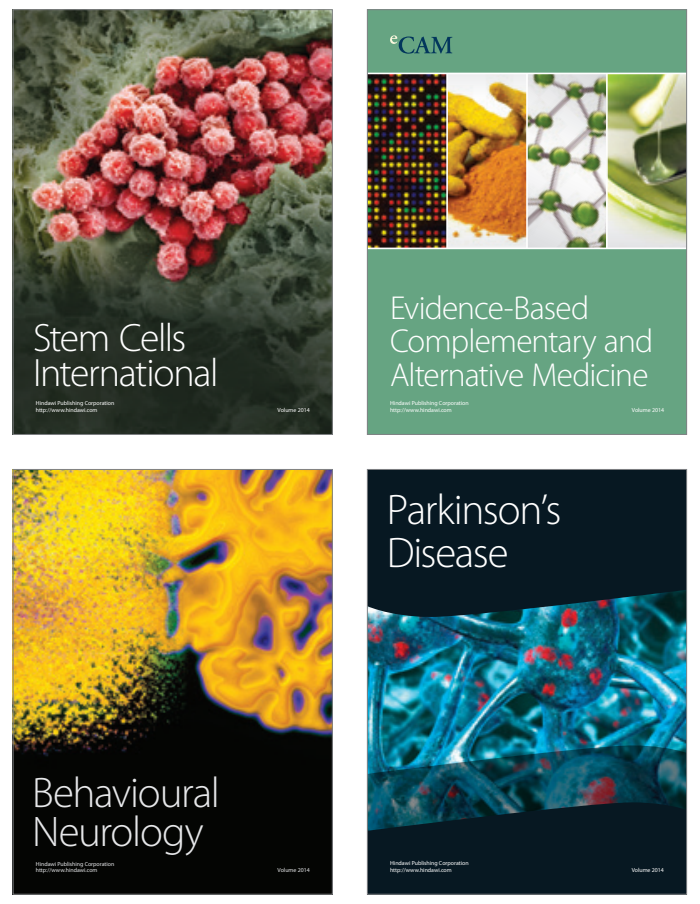
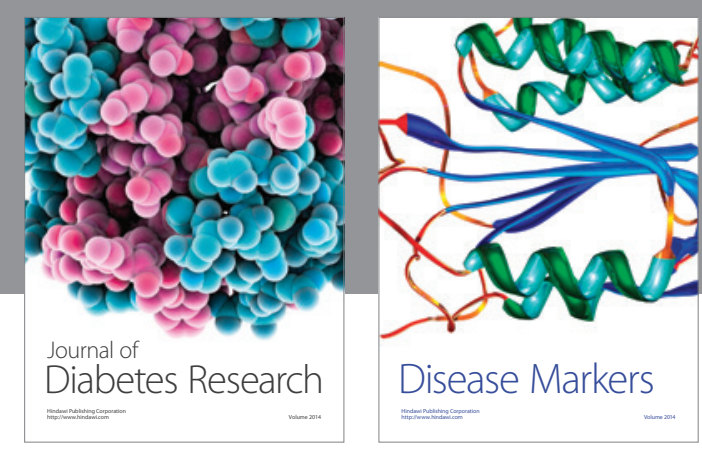

Disease Markers
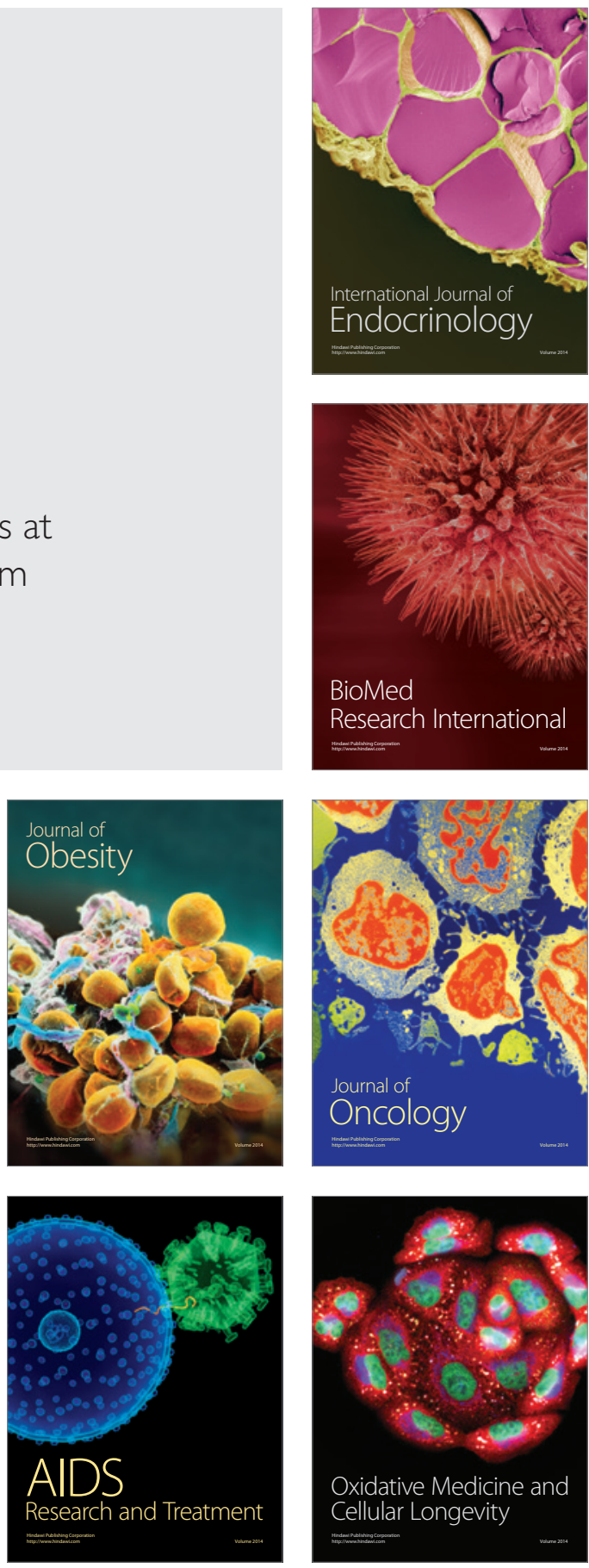